\title{
Spirituality as Ideological Concept of Modern Education
}

\author{
Gaponyuk P.N. ${ }^{1}$, Mareev V.I. ${ }^{2}$, Karpova N.K. ${ }^{2,}$, Dyuzhikov S.A. ${ }^{2}$ \\ ${ }^{1}$ Russian Academy of Education, Moscow, Russia \\ ${ }^{2}$ Southern Federal University, Rostov-on-Don, Russia \\ *Corresponding author: karpova_nk@mail.ru
}

Received November 05, 2013; Revised November 26, 2013; Accepted December 04, 2013

\begin{abstract}
The article covers the phenomenon "spirituality" seen as ideological concept of modern education, determining its deep senses that are shaped in the form of ideologemes. The performed activity of a person and its estimation in terms of paramount values are considered to be criteria of ideologemes acceptance. Methodological aspect of personal spiritual revelation is seen by the authors as one of the basic directions in pedagogy, shifting the focus of studies to hermeneutic principles in studying spiritual experience. The core of pedagogical activity is to reveal deep inner world of an individual by applying hermeneutic approach.
\end{abstract}

Keywords: ideology, concept, spiritual development of personality, communication, spirituality

Cite This Article: Gaponyuk P.N., Mareev V.I., Karpova N.K., and Dyuzhikov S.A., "Spirituality as Ideological Concept of Modern Education.” American Journal of Educational Research 1, no. 10 (2013): 436441. doi: 10.12691/education-1-10-5.

\section{Introduction}

The article is devoted to outlining methodological preconditions of personality spiritual revelation theory, worked out by the authors [1]. The heart matter of spirituality is characterized by the notion "concept" (sign). Semantic content of spirituality as a sign is comprised in iconic codes - appeal, request, game, meditation, and network. These codes are paramount values, arranging axiological vector of spirituality.

Iconic codes (the term introduced by the authors [2]) are basic forms of the most ancient archetypes underlying the universal thesaurus of senses. Communication stipulates uncovering iconic codes from the outside. Iconic codes are transformed into the form of communicative archetypes fixed in genetic memory of mankind at the level of cultural genotype patterns. Iconic codes conceptualize a new vector in pedagogical science hermeneutics of spiritual experience (the authors' term [2]).

Developing personal spirituality is considered to be ideological concept of modern education which methodological characteristics, in the authors' interpretation [3]), can be defined in terms of cybernetic, communicative and figurative-interpretive approaches.

The purposes of the article are as follows: to describe the authors' approach [4] to methodological aspect of spiritual development of a personality as the key direction of pedagogical science and education; to define iconic codes by the concepts of a new vector of pedagogical science - hermeneutics of spiritual experience (the authors' term [1]); to examine procedural aspect of work with ideologemes (the authors' term [2]). As for the basic methods of theoretical analysis, they include: interpretation, metaphorization and conceptualization.

\section{Ideology in the Context of Personal Spiritual Development}

Ideology (derived from Greek $1 \delta \varepsilon \alpha$ - prototype, idea; $\lambda$ oyos - word, reason, doctrine) means the doctrine about ideas. Ideology is a set of the typified ideas united by an overall aim, rules of their creation. Its characteristic features include: structure, distribution methods, estimation criteria and some others. The term "ideology" may have various interpretations. Thus, A.L.C. Destutt de Tracy who coined this term and introduced it into scientific world, considered ideology as a system of knowledge about origins of morals, politics and law.

According to A.L.C. Destutt de Tracy, ideology is a doctrine about general regularities in the origin of ideas and contents of sensual experience. According to K. Marx, ideology is false consciousness expressing specific interests of a certain class, posed as interests of the whole society [5]. According to Karl Mannheim, ideology stands for the deformed reflection of social validity expressing interests of certain groups or classes, aspiring to save the existing order of things; is opposed to utopia. Ideology by Roland Barthes is a modern meta-language myth, connotative system, attributing indirect meaning to objects and socializing them [6].

Function of ideology is to form people's consciousness and rule them by influencing their consciousness [7]. Ideology creates and introduces certain conscious stereotypes into people's minds that are reflected in behavior stereotypes, using science as means of achieving the goal in view. World religions can be seen as examples of ideologies of global, epoch-making scale. However, religion and faith mean something deeply personal. The appeal "to believe" is aimed at an individual, whereas 
ideology is aimed at a class, people, and mankind. There occurs a question: whether it is possible to create the theory which would unite private, personal with general, universal? In terms of what conceptual framework is it possible to shape such doctrine? What is the role of theory in the life of the state, society, and an individual?

Let us give a positive answer to the first question: creation of such theory is possible in the context of interaction of secular and spiritual pedagogy. Spirituality, or spirituality development, is the heart matter of this theory. The answer to the second question is pedagogy. Revealing spiritual "I" is possible as part of interaction of an individual with Another person, the Others. On the hard way to spiritual perfection, one needs pedagogy of assistance and support. In this respect, pedagogy can be considered as the means, the tool of achieving the object in view. The answer to the third question is already hidden in the answer to the second one. The theory of personal spiritual development is a kind of ideology that shapes not only personal well-being, life of the society, the state, but also the world community as a whole. It is epoch-making ideology of spiritual interaction between the people united by the general value implications: main meaning of life is life itself; the main value - is personality, human life; knowledge, activity, creativity make up the core components of human life.

Let us expand on methodological aspect of personal spiritual development in the authors' opinion [8]. The essence of spirituality is preconditioned by the context describing a certain person. Meanwhile, wise energy of spirituality, energy of spiritual consciousness is the parameter that determines potential displays of an individual. Energy of spiritual consciousness is universal, inherent and is assumed to result in active cogitative activity of a person in forms of an image, a symbol and a concept.

Personal images and symbols can be variable, temporally caused and correlate to the culture context. Thus, figurative-symbolical context of personal being is characterized by reproductive, constructive and creative aspects. Reproductive pattern functions in the "mode" of reconstruction. Aims of creative aspect include creating artifacts of the culture presented in various spheres of spiritual activity of an individual: scientific and social domains, arts, etc. Constructive and creative aspects are interconnected: constructive aspect is provided by attributive potential of the culture, creative - by using cross-cultural universals in order to create and, as a result, to update various modules, making up potential of the modern culture.

Spiritual consciousness of a person aimed at coining a concept is an essence of personality development. Development vector is characterized by the universal and, simultaneously, the unique. Universality is determined by the prevalent cultural genotype, uniqueness - by revelation, reaching one's potential, self-revealing and perfection of various projections of an image, a sample from cultural genotype by means of creative activity.

Concept (derived from Latin) - stands for a sign, heart matter of personality's spirituality and is characterized by internal context. It is displayed outside as part of versatile communication. So, energy of spiritual consciousness shapes procedural characteristic features of spirituality of an individual, results in cogitative activity in the form of coining a concept, characterizes the level of spiritual development of a person.

\subsection{Iconic Codes - Key Points of Spirituality}

Referring to spirituality as a sign, by which each person is "initially marked", demands singling out iconic codes (appeal, request, game, meditation, and network), describing universals of cultural genotype that form the background, the core of spirituality.

Spirituality development means evolving culture. Notional features of the above mentioned processes are caused by connotation of iconic codes. Evolutionary development of culture potentiated by personal spirituality development of many people, increases connotative background of iconic codes, differentiating them at the level of tendencies, styles, kinds of art, genres, space coordinates (geographical transmission) $[8,9]$.

Culture artifact is an image of cultural genotype that projects it outside and reflects it as a mirror. Projection of an image - essence of cultural genotype - is one of personal components. Genotype becomes a part of an individual, whether he wishes to accept or not to accept the reflected image. We consider iconic codes as paramount values, making up axiological vector of spirituality structure. Connotative background of iconic codes forms the vector of spirituality contents, integrating universal and personal projections of images of the cultural genotype reflected in culture artifacts.

The process of escalating connotative background predetermines some changes, renewal of cultural genotype. Vector orientation of renewal is to reach the highest model of perfection, that is, include creativity code into the universals. Creativity code opens in front of each person the road to infinity, to achievement of the highest spirituality, makes it possible to come nearer to higher reason. Thus, creativity characterizes the vector of spirituality development [1].

Energy of spiritual consciousness is primarily inherent to a person; however, each individual has one's own scale of spirituality; temporal characteristics of this process are also different. Primary reflection of culture artifact image projection occurs at different acquisition levels of different individuals: conscious and subconscious.

Conscious acquisition makes creative activity dynamic; subconscious performs the function of "storage" with a possible projection in future, including quite definite future, as reflected in children, grandchildren, greatgrandchildren, etc. Extreme cases, such as wars, revolutions lead to setting cultural genotype in the mode of "storage". Temporal failures in private human life can be caused by stressful situations, adverse emotional background in the family, at work, etc. Thus, cultural genotype, determined by vectors of space, time, values, culture artifacts, iconic codes, creativity treated as means of spirituality development, makes up alive organism, characterized by the concepts "reflection, activity, preservation". Reflection and preservation of cultural genotype means uncovering iconic codes. Activity, including creative one, means revelation. The sequence "reflection - preservation - revelation" makes infinitely repeating processual line, characterizing meaning of human life.

Iconic codes can be defined as basic forms of the most ancient archetypes underlying the universal thesaurus of 
senses. Communicative situations stipulate uncovering iconic codes outside. Iconic codes are transformed into the form of communicative archetypes fixed in genetic memory of mankind. Iconic codes (communicative archetypes) can be considered to be forms of communication. An individual starts a dialogue with the nature, the world, other people, obeying the instinct reflected in the phenomenon of communicative attraction. Let us specify that singling out communicative archetypes is based on phenomenological status of the notion function [[3]: 43-52].

Communication as the process of mutual emphatic penetration of people's spiritual contexts creates energy that has an ability to preserve spiritual essence of phenomena and attributes of human life. Communication provides spiritual unification of the people who inherently possess spirituality and ability for interaction. Such unification of energy field has both positive and negative effects. A person often needs to make volitional efforts to overcome negative aspects and increase positive dynamics of personal displays aimed at preservation of Spirituality seen as intrinsic basis of human life. Hereby, spirituality as a sign is defined by such concepts as opposition and struggle. A human being is a complete cybernetic system of socio-biological issues, aligned by the phenomenon of Spirituality. Meanwhile, centrifugal vectors constantly infringe the structure, making it dynamic due to development of the culture, civilization. However, paramount values that determine the content aspects of spirituality, condition self-adjusting, self-correction, selfimprovement of the system. The authors' interpretation of cybernetic approach can be seen as the methodology providing spiritual revelation of a person [[3]: 113-116].

The word combination "cybernetic system of spirituality” [8], suggested by the authors of this article, may sound rather unusual. The structure of the system is determined by vector orientation, the content is valuefocused and caused by the context of culture. Dynamics of its development is shaped by such factors as self-adjusting, self-correction and self-improvement. Functioning of this system is provided by activity and creative outpouring of an individual.

The basic principles providing existence, functioning and development of the phenomenon of spirituality cybernetic system are as follows:

- Divergence principle caused by the existence of iconic codes;

- Value orientation principle characterized by connotative background of culture;

- Principle of creative organization of human activity, contributing to synergetic character of the system.

The functioning system algorithm makes up the essence of spiritual activity of a person. It consists in infinitely repeating chain of interconnected and interdependent concepts comprehended by an individual: opposition struggle - getting outside - unification. All of them are presented at the level of internal dialogue with the self. Iconic code "appeal" is granted dynamic acceleration described by the concept "struggle". Opposition, contradictions, "struggle”, including "internal struggle", all these features make up the way of human existence in the world of spirituality.

The authors; tem "social spirituality" is a kind of energy field able to save projection of spiritual essence of phenomena, events and attributes of human life [10]. Each of us creates one's own real life, but, at the same time, abstract spiritualized world. Energy field of social spirituality forms a set of the worlds, by joining them we enter into the context of spirituality of another person, many other things, and in this way we enrich our spiritual "I" without even realizing it.

Energy field of social spirituality is shaped by the epoch, culture, life realities of people living in certain historical era. But, at the same time, it can "include" spiritual projections correlated with a number of epochs, cultures, life realities. It occurs at the moment of mediated communication of a person with the founders of philosophical doctrines, theories, pieces of art. This idea makes it possible to define energy field of social spirituality as the space of infinity uniting spiritual projections (essence) of people, their original, true background.

This energy field is invisible. It is a layer of deep private world of an individual, but certain deeds, acts, dayto-day activity of each person and society as a whole enable to evaluate Spirituality of real society. So, there exists a real person, there exists his/her spiritual essence. Internal dialogue between a real and spiritual persons forms micro-space of energy field. Communication with Another human being, with Others, expands interacting spaces of real and spiritual kinds. This refers to macrospace, while the mediated, timeless communication with Others, can be referred to as meta-communication. In meta-communication there is a real person and his/her spiritual projection, spiritual essence, entering emphatic interaction with spiritual projections, or life worlds of the people who do not really exist. It means that energy field of social spirituality forms two levels: the bottom level spiritual projections, and the top level - realities of the modern world. The bottom spiritual level initially has a greater energy potential as spirituality is a sign, the true essence of an individual. The top level is subjected to criteria analysis. It is the measure of spirituality of society, characterized by such concepts as good attitude, kindness, mercy, compassion, love, etc. Full revelation of spiritual self of a person at the level of "positive aspect" makes it possible to harmonize the levels specified above. Achieving balance is the way to reach highest Spirituality. This way is infinite: generations change and this way begins all over again; but each new generation begins its way from the "point" of greater growth than the previous one. This is the law of development, it is firm and inviolable. Another point is that dynamics of growth can be various. If certain conditions for spiritual development are created in society, the process is characterized by the vector of dynamic spiritual development. Dynamics is provided only in case the following issues are taken into account:

- Pedagogical science and practice are aimed to give an outline of the concepts that make up phenomenon of spirituality development and work out pedagogical technologies allowing everyone to reveal one's spiritual projection, to understand, comprehend and accept the fact of the two worlds existence: the real world and the world of spiritual kind; to realize, that the real world created by people is the reflection of spiritual one;

- Methodology of secular and spiritual pedagogy shall state the "dominants" of integrating the concepts and 
theories of theology and pedagogy, philosophy and sociology;

- Spiritual development of a person should become methodological feature, determining conceptual and applied aspects of projecting in education, an idea of spiritual "revelation" shall demand for a new conceptual device;

- Nurturing in education shall be considered as process of personal spiritual development, characterized by procedures of revealing iconic codes in versatile activity carried out at deep layers of real and spiritual kinds.

\subsection{Scope of the Concept "Hermeneutics of Spiritual Experience”}

As the way to cover phenomenon of spirituality revelation, we find it relevant to set forth a new vector of pedagogical science - hermeneutics of spiritual experience (the authors' term [10]). Iconic codes “meditation”, "request" and "game" make up this phenomenon. The code "meditation" at the revelation stage brings into focus the process of self-knowledge which is carried out while referring to Spiritual self, to Others, as part of interpretation and understanding spiritual self of Another person, Others. During each personal revelation, iconic code "meditation" is transformed into the form of communicative archetypes, creating energy field of personal spiritual projections. An individual simultaneously creates one's own spiritual projection and gets to understand contexts of other people's Spirituality. Interpretation and understanding of deep meaning of Other people's Spirituality contexts enriches our own spiritual self. Revealing "meditation" iconic code is determined by semantic dynamics of such processes as interpretation, understanding, acceptance (nonacceptance).

Inconsistent essence of spirituality also presupposes the fact of aversion. But interchange all the same takes place in the context of multivariate Spirituality field. Revealing meditation code means self-profound experience, contemplation, feeling free from ordinary fuss and merging into the nature, the world, the Universe. Meditation stands for familiarizing with the Divine Principle, highest spirituality seen as the center of highest values. While disclosing "meditation" code, the distinction between "speaking" and "listening" is eliminated: it is a situation of real silence and spiritual unification, being "on-line” with highest frequency and infinity.

Iconic code "request" is predetermined by transformation into communicative archetype and correlated with ethical attitude of communication participants to each other. "Request" code stands for the categories respectfulness, cordiality, and openness. It is the code of the etiquette of spiritual dialogue between people.

Iconic code "game", in fact, means entry of a person into notional field of subconscious context. Images act as players in this playground. The sphere of personal subconsciousness stores everything that has been apprehended: analogues (images) perceived as something clear, well-known, and not absolutely clear, the unknown. Revealing iconic code of game consists in revealing variants of something known in order to comprehend the unknown, not clear in the existing personal notional context. Notional field of a person is not limited by the existing frameworks; it interacts with notional fields of other people. In this way, images are corrected in a necessary way: one is left out, others appear, movement on the playground is structured, or, in other words, system decomposition takes place. At this deep notional level personal development is possible. This game is infinite; its complexity and variability are provided by new impressions that reflect figurative form of world view and are saved in the sphere of sub-consciousness of a person.

Figurative-interpretive approach can be considered to be methodological basis of hermeneutics of spiritual experience. Its key principles include the following ones:

- Movement of personal sense to creating a new image, "new players";

- Principle of selecting some objective-semantic phenomena that can correlate with spirituality sphere for interpretation procedures;

- Principle of structuring objective informative and communicative space, using resources of the global network Internet.

The algorithm resulting in the creation of a new image, in fact, is parameter of spirituality semantic development orientation and is presented by the following sequence of steps: perception of an object (translating external into internal), figurative representation of an object (external aspect), interpretation (understanding), image transformation into a new image. Figurative representation of an object (external aspect) means real projection; a new image is a spiritual projection.

Thus, methodological characteristics of spirituality development are established by the context of the following approaches: cybernetic, communicative and figurative-interpretive. Spirituality is given to a person initially, but it is necessary to reveal it in the projection of comprehending "cultural genotype" phenomenon. Spirituality is unique and at the same time universal. Universality stipulates the essence of spiritual revelation, uniqueness - spiritual self-disclosing. Creativity is the unifying vector. Creativity is the core of spirituality, highest sense of human life.

Thus, new ideology means the theory of spiritual revelation of a person - one of basic directions of pedagogical science that, in this respect, obtains a new status. Pedagogy, solving problems of personal development of spirituality seen as the sign by which each person "is initially marked", focuses on developing one's culture. Notional features of the named processes are caused by iconic codes connotation - appeal, request, game, meditation, network, describing universals of cultural genotype that make up the basis, core of spirituality.

Pedagogical activity should be aimed at revealing deep private world of an individual basing on conceptualized hermeneutics of human spiritual experience. Application of the authors' interpretation of hermeneutic approach [8] means creating a spiritual ideologeme (spiritual ideologemes) in people's minds at levels of understanding, interpretation (elucidation) and acceptance as guidelines for actions, activity in general.

\subsection{Spiritual Ideologeme. Technological Scheme for Working with Ideologemes}


We define spiritual ideologeme (the authors' term [1]) as an idea that is dementalized by personal and highest senses making up non-segmented semantic unity. The task of pedagogy is to define, shape and distribute ideologemes, to provide their personal judgments, as well as to expand the range of technologies of "understanding" pedagogy. Ideologemes can be seen as guideline for practical activities of an individual person, meta-language, original connotative system, that serve to give indirect meaning to objects by means of subjective perception and socialization of life realities.

An ideologeme should be presented at the levels of visualization, voiced text and kinesthetic. That is, as a matter of fact, an image having three projections. Representation of an image and "deep" work with it is carried out by a person both in real life and in the computer-mediated space of global Internet network. The purpose of pedagogical activity consists in developing meta-language of ideologemes, their pedagogical design by multimedia means, help and support of an individual, arranging one's unique mental world including ideologemes. It is also vital to create the environment providing interaction of the mental worlds enriching with that meta-language with versatile subjective projections of ideologemes.

Technological chain-scheme of work with ideologemes is the following: registration, three-level projection of an image, understanding, interpretation, transformation (into a new image), registration of a personal ideologeme, interaction with Another person (Others), guided by ideologemes and adjoining ideologemes of Others. This process repeats further on infinite number of times. The task of a teacher is to "start, initiate" the movement and correct it as required, taking into account that he/she is also included into the algorithm of work with ideologemes presented above.

The slogan "Lifelong Education!” makes it urgent to define and set forth ideologemes since childhood period and up to the period of senior age. As a matter of fact, ideologemes can be treated as multimedia "books of life", created according to the laws of morals, the good, justice. Each person, opening new files, new pages of one's own life, realizes the individual program of spiritual life. Everyone has it, but it is necessary "to start" it, give it acceleration, make it dynamic. Thus, secular and spiritual pedagogy should be incorporated for defining ideologemes and creating the encyclopedia of metalanguage in multimedia format. We shall consider procedure of work with ideologemes. Three multimedia projections of an image can be represented by means of music, painting, and poetry. Perception, understanding, interpretation and further transformation of an image result in subjective representation of an ideologeme. It is possible to check whether an ideologeme has become a kind of ruling principle for practical activities in certain situation which can be modeled by a teacher or created by life circumstances.

Ideologemes are, in fact, modern analogues of biblical morals, highest everlasting human values. They should be understood, interpreted and returned into the world of life realities as part of human activity. Criteria of ideologeme acceptance can be the performed activity of a person, estimated in regard to the highest values.

Process of "inclusion" of an individual into the process of ideologemes' understanding and interpretation is both complicated and simple. For children is a game, a kind of computer game. For teenagers it is also a game, but with the use of objects transforming technologies that strengthen their creative background. For adults it can also be a game, understanding and interpretation of one's own self as a dialogue between real "I" and spiritual "I". For a person who has entered so-called third age, it is a game of ideologemes projections memoirs from childhood, adolescence, youth, and adulthood periods. Ideologemes are repeated but their connotative background extends and enriches, i.e. their "projection field". Ideologemes should get into human life since early childhood, become an urgent necessity, and accompany an individual through all his life, making life sense and decor at the same time.

Ideologemes should be includes in education contents of all steps and levels. It's not enough just to enrich education content with ideologemes, though. It is necessary to develop pedagogical technologies of so called "understanding" pedagogy [12] aimed at interpretation and understanding. These are technologies of understanding pedagogy, hermeneutics of spiritual experience [10]. Preparation of teachers, capable to realize the development and interpretation of ideologemes in terms of asynchronous training is considered to be quite relevant. Hence, development of new pedagogical standards granting qualification referred to as "teacher of spiritual ideology" can be set forth. Meanwhile, information-communicative space for work with ideologemes at the level of practical development and subsequent theoretical grounding should be created.

In modern socio-cultural situations ideologization in education is an absolute must. Spiritual space, space of spiritual ideology is left blank or is locally filled with impractical ideas, promoting escape from life reality into the world of something unreal and mystical. We'd like to note the fact that we have huge experience of introducing ideology into people's minds. Topical aspects of research include its thorough analysis, selecting the best technologies and duplicating them to solve the purpose in view. The experience gained in the sphere of advertising and PR technologies in this aspect can be quite helpful. It is also necessary to consider some features of the new generation for whom computer "cliques" are supposed to be signals for initiating a dialogue, and texting is the form of expressing ideas, emotions, and feelings. But these "minuses" of modern civilization could be turned into "plusses". Notional range of the phenomena that express carefully selected and figuratively presented ideologemes, correlated with spirituality sphere, should be present in life of any child, teenager, and adult everywhere: in screen savers and mobile phones' pictures, in advertizing leaflets and TV commercials.

From the point of view of highest aesthetics, one might find it ignoble, but from the point of view of vital necessity to turn the person to the world of spiritual realm such methods can be justified. Highest values, being transformed into the low shape and, in this way, preserving their high essence, will be close to people. In this way we will give everybody an opportunity "to contact" with ennobled in our usual, ordinary life filled with minor problems. An opportunity to understand, interpret and return "outside" the comprehended idea, which already includes the particle of spiritual self of a person, will be created. 
It is necessary to take into account the fact that updating scientific knowledge in modern situation takes place so promptly, that ideologemes' existence on temporal level is short-term. Constantly updating context of life, social and cultural realities also make the process of ideologemes' changes dynamic. Thus, we need to work all the time at definition and figurative embodiment of constantly changing ideologemes, both existing and appearing in reply to the challenges of global civilization.

We'd like to mention that work with ideologemes will enable to present the semantic contents of concepts at the generalized level, providing systematized framework of pedagogical categories and concepts in order to overcome the "disorder" of conceptual variety existing today in the context of various approaches, theories and concepts. Interpretation of ideologemes essence on practical and theoretical levels determines the nature of personal projection of spiritual experience hermeneutics. The given format provides orientation of notional development of spiritual self at the level of its content.

Thus, spirituality can be considered as ideology of modern education, determining highest senses, values, regulations of its functioning and development, providing steady quality standard of its content in conditions of constantly varying reality.

\section{Conclusions}

1. Revealing spirituality of a personality is an ideological concept of modern education.

2. Iconic codes characterize the universals of cultural genotype and make up the spirituality basis. Connotative background of iconic codes forms the vector of spirituality, integrating universal and personal projections of cultural genotype images.

3. Process of escalating connotative background stipulates updating cultural genotype. The updating vector is aimed at approaching highest sample of perfection characterized by inclusion into creativity code universalities. Creativity shapes the vector of spirituality revelation as a self-adjusting, self-correcting, selfimproving (cybernetic) system.

4. The concept of spirituality revelation stands for a new vector of pedagogical science - hermeneutics of spiritual experience, figuratively-interpretive approach being its methodological background.

5. The idea, characterized by personal and highest senses that make integrated semantic unity, is defined by the category "spiritual ideologeme". Spiritual ideologeme is a kind of individual program of spiritual human life created in accord with the laws of morals, welfare and justice. Procedural aspect of work with ideologemes brings into focus the idea of developing educational standards of a new pedagogical specialty, referred to as "teacher of spiritual ideology".

\section{References}

[1] Karpova, N.K. Methodological Concepts of the theory of Personality Spiritual Revelation. Modernization of Education. In: Problems of Modern Education. Issue 2. Nurturing, Education and Spiritual Revelation of a Personality (in Rus.). Rostov-on-Don: published by Pedagogical Institute of Southern Federal University, 2010.

[2] Karpova, N.K. Spirituality as Ideology of Modern Education (in Rus.) News of Southern Federal University. Pedagogical sciences, 2010, № 12.

[3] Gaponyuk, P.N., Karpova, N.K. and M.V. Lebedeva. Organization of the Environment of Real and Virtual Teaching a Foreign Language (in Rus.) Rostov-on-Don: published by Pedagogical Institute of Southern Federal University, 2011.

[4] Karpova, N.K. Methodological Characteristic of the Problem Field of Spiritual Experience of a Person. In: Modernization of Education: Problems of Modern Education. Issue 1. Education: ideology, methodology, contents (in Rus.). Rostov-on-Don: published by Pedagogical Institute of Southern Federal University, 2010.

[5] Marks, K., Engels, F. Selected Works (in Rus.), Volume. 3. Moscow, 1955. p. 25.

[6] Politology: System Managing Approach (in Rus.) Moscow: Glushchenko V.V., 2008, 160 p.

[7] Zinovyev, A. Philosophy as Part of Ideology. 2002. [Online] Available:

http://www.rags.ru/akadem/all/17-2002/17-2002-12.html

[Accessed: Dec 01, 2012].

[8] Karpova, N.K. Spiritual Personality Revelation: methodological aspect. In: Development of Personality in Educational Systems: proceedings of XXIX international psychological and pedagogical readings (in Rus.). Rostov-on-Don: published by Pedagogical Institute of Southern Federal University, 2010.

[9] Karpova, N.K. Spirituality as Ideological Basis of Modern Education. In: Ideological Aspects of Methodological Content of Scientific Researches: proceedings of All-Russian Methodological Seminar (in Rus.). Moscow, 2010.

[10] Karpova, N.K. Spirituality, Personality Spiritual Revelation and Ideology of Modern Education. In: Proceedings of Internet Conference "Spirituality and Patriotism as Ideology of Modern Education" (in Rus.) [Online] Available:

<http: // www.econf.rae.ru/conference/660> [Accessed: Dec 05, 2011].

[11] Karpova, N.K. Methodological Reference Points of Pedagogy of Hermeneutic Experience. In: Modern Directions of Development of Pedagogy as Humanitarian Scientific Discipline: proceedings of All-Russian Methodological Conference-seminar (in Rus.). Krasnodar: published by Kuban State University, 2009.

[12] Karpova, N.K. Stating the Problem of Modern Education Idealogization. Psychology and Pedagogics in the System of Modern Knowledge (in Rus.). In: Proceedings of V International Scientifically Conference held in Moscow, December 27-28, 2012, in 2 volumes: v. 2. Published by Publishing House "Spetskniga", 2012. p. 93-99. 